\title{
Low back pain and widespread pain predict sickness absence among industrial workers
}

\author{
Tone Morken*1, Trond Riise ${ }^{1}$, Bente Moen ${ }^{1}$, Signe HV Hauge ${ }^{2}$, \\ Solrun Holien², Anne Langedrag², Svein Pedersen², Inger Lise L Saue ${ }^{2}$, \\ Guri M Seljebø $\varnothing^{2}$ and Varughese Thoppil ${ }^{2}$
}

Address: ${ }^{1}$ Section for Occupational Medicine, University of Bergen, Norway and ${ }^{2}$ The Aluminium Industry in Norway, Oslo, Norway

Email: Tone Morken* - tone.morken@isf.uib.no; Trond Riise - trond.riise@isf.uib.no; Bente Moen - bente.moen@isf.uib.no;

Signe HV Hauge - signe.helene.hauge@hydro.com; Solrun Holien - solrun.holien@elkem.no; Anne Langedrag - anne.langedrag@arcus.no;

Svein Pedersen - svein.pedersen.HAL@hydro.com; Inger Lise L Saue - inger.lise.liahjell.saue@hydro.com;

Guri M Seljebø - guri.seljebo@hydro.com; Varughese Thoppil - tone.morken@isf.uib.no

* Corresponding author

Published: 04 September 2003

BMC Musculoskeletal Disorders 2003, 4:21
Received: 17 February 2003

Accepted: 04 September 2003

This article is available from: http://www.biomedcentral.com/I47I-2474/4/2I

(C) 2003 Morken et al; licensee BioMed Central Ltd. This is an Open Access article: verbatim copying and redistribution of this article are permitted in all media for any purpose, provided this notice is preserved along with the article's original URL.

\begin{abstract}
Background: The prevalence of musculoskeletal disorders (MSD) in the aluminium industry is high, and there is a considerable work-related fraction. More knowledge about the predictors of sickness absence from MSD in this industry will be valuable in determining strategies for prevention. The aim of this study was to analyse the relative impact of body parts, psychosocial and individual factors as predictors for short- and long-term sickness absence from MSD among industrial workers.

Methods: A follow-up study was conducted among all the workers at eight aluminium plants in Norway. A questionnaire was completed by 5654 workers at baseline in 1998. A total of 3320 of these participated in the follow-up study in 2000. Cox regression analysis was applied to investigate the relative impact of MSD in various parts of the body and of psychosocial and individual factors reported in 1998 on short-term and long-term sickness absence from MSD reported in 2000.
\end{abstract}

Results: MSD accounted for $45 \%$ of all working days lost the year prior to follow-up in 2000 . Bluecollar workers had significantly higher risk than white-collar workers for both short- and long-term sickness absence from MSD (long-term sickness absence: RR $=3.04,95 \% \mathrm{Cl} 2.08-4.45$ ). Widespread and low back pain in 1998 significantly predicted both short- and long-term sickness absence in 2000. In addition, shoulder pain predicted long-term sickness absence. Low social support predicted short-term sickness absence $(\mathrm{RR}=1.28,95 \% \mathrm{Cl}$ I.I I-I.49).

Conclusions: Reducing sickness absence from MSD among industrial workers requires focusing on the working conditions of blue-collar workers and risk factors for low back pain and widespread pain. Increasing social support in the work environment may have effects in reducing short-term sickness absence from MSD. 


\section{Background}

Sickness absence is used in occupational medicine as an important indicator of morbidity. As healthy functioning is a mixture of social, mental and physical status, sickness absence may be used as an integrated measure of healthy functioning and coping in working populations $[1,2]$. Musculoskeletal disorders (MSD) represent an important cause of morbidity and disability. Currently $40 \%$ of worldwide work-related health costs are attributed to MSD [3]. In Norway, MSD have been the dominant cause of sickness certification by a doctor, whether measured by incidence, duration of single episodes or number of days of work lost [4]. A study of sickness certification concluded that more than one third of the health problems causing sickness certification were potentially preventable [5]. The potential for prevention was assessed to be highest when the diagnosis underlying sickness certification was MSD.

Many episodes of sickness absence have a multifactorial background and many are not, or only marginally, related to the work environment [6]. At the occupational level, several factors influence sickness absence from MSD, such as the physical and psychosocial environments [7-9], job title $[8,11]$, and the absenteeism culture at and outside work. At the individual level, age, gender and diagnosis [10] have been associated with sickness absence from MSD.

The rates of sickness absence and being awarded a disability pension from MSD vary in different occupations and tend to be higher among blue-collar workers than among white-collar workers [12]. The high sickness absence rates in certain occupations might be caused both by socio-economic difference [13] and by high occupation-specific morbidity $[14,15]$. Factors associated with the varying effects of disease include difficulties in meeting requirements for physical fitness, lack of control over the work situation and opportunities to cope [16]. However, little is known about the relative impact of pain from various body parts, psychosocial work environment and individual factors on sickness absence from MSD. The prevalence of MSD in the aluminium industry is high, and there is a considerable work-related fraction [17]. More knowledge about the predictors of sickness absence from MSD in this industry will be valuable in determining strategies for prevention.

Short- and long-term sickness absences are often distinguished. It is generally accepted that subjective factors play a larger role in short-term absence than in long-term absence [18]. Individuals' short-term sickness absence might be regarded as a coping mechanism that prevent serious illness in the longer term rather than as directly expressing poor health [19]. In Norway, employees may be absent from work from sickness 12 days per year without needing certification by a physician. Long-term absence has a greater impact on social expenditure than does self-certified absence, and the predictors for shortand long-term absence might therefore differ.

The aim of this study was to investigate the relative impact of MSD in various parts of the body and psychosocial and individual factors for short- and long-term sickness absence during one year among industrial workers.

\section{Methods}

\section{Study design and data collection}

The study population consisted of workers at eight aluminium plants in Norway. The management of the plants wanted more knowledge about how to reduce MSD and sickness absence. As part of an intervention study to improve musculoskeletal health [20], the workers completed a self-administered questionnaire in $1998(n=$ 5654 , response rate $92 \%$ ). These workers were followed up in a new study in 2000. The questionnaire included questions on sickness absence, job title (operator, manager or office worker), occurrence of MSD in the previous 12 months (1-year prevalence), age, gender, height, weight, smoking status (yes - no), physical activity, shift work, job demands, job control and social support. We analysed the effect of the predictors reported in 1998 on sickness absence reported in 2000.

The questionnaire was filled out anonymously, but the workers were asked to create a code to enable the individuals in the two surveys to be linked. The employees off work at the time the study was performed (2 months) were not included. The job titles were categorised into blue-collar workers (operators) and white-collar workers (office workers and managers). Smoking was dichotomised into current smoker or non-smoker. The question about physical activity was: "How much physical activity do you get during the week (such as walking, jogging, bicycling, swimming, gymnastics, ball-playing)?". The answers were categorised into 1) less than 2 hours, 2) 2-5 hours or 3 ) more than 5 hours.

\section{Musculoskeletal disorders}

The prevalence of MSD was recorded according to a modified version of the Standardised Nordic Questionnaire for the analysis of musculoskeletal symptoms [21]. The questions about MSD were phrased as follows: "Have you at any time during the last 12 months had trouble (ache, pain, discomfort) in: __ (Appendix [see Additional file 1]). The list included the neck, shoulders, elbows, hands, upper back, lower back, hips, knees and feet. A five-point scale ranging from "never" to "very often" was used instead of the dichotomised alternatives "yes" and "no" used in the original version. The scale from "never" to 
"very often" has been tested for low back pain and found to correspond well to answers in the Standardised Nordic Questionnaire categorised into specific numbers of days of pain [22]. An index called widespread pain was constructed as the number of body parts that caused pain. For this index the frequency of pain was dichotomised in no pain (never, seldom, sometimes) and pain (often or very). The index ranged from 0 to 9 . High score means frequent pain from many body parts.

\section{Psychosocial factors}

The psychosocial work factors were measured using a Norwegian translation of the short Swedish version of the Job Content Questionnaire [23] developed from the job demands-control-social support model of Karasek \& Theorell [14]. Psychological job demands were measured using five questions. High demands were related to working rapidly and hard, excessive work, insufficient time to work or conflicting demands. Control (decision latitude) was measured by six questions related to learning new things, creativity, skills, task variety and the quantity of repetitive work. Social support was measured by six questions related to the atmosphere in the working environment and help and support from co-workers and supervisors. All questions were scored on a four-point scale.

The scores of the items on psychosocial work factors were summarised and transformed into three scales of job demands, job control and social support ranging from 0 (equivalent to "no", "never" or "do not agree" as the lowest score for various items) to 1 (equivalent to "yes", "often" or "agree" as the highest score for various items).
Thus, higher scores on the three scales represent higher job demands, higher job control and higher social support. The score 1 indicate the best possible score. The reliability and validity of the responses collected using the Job Content Questionnaire have been tested and found to be satisfactory [24]. Internal consistency was acceptable in this study, as Cronbach's alpha coefficients were 0.71 for job demands, 0.74 for job control and 0.82 for social support. In this study we used job strain defined as the relationship between job demands and control. A variable job strain was calculated by dividing job demands plus 1 by job control plus 1 to avoid the problem of dividing by zero. The job strain variable was dichotomised by the median as a cut off point.

\section{Data on sickness absence}

We used self-reported data on sickness absence. The questions about sickness absence (the dependent variables) were phrased as follows: "Have you had any sickness absence in the past 12 months?" (yes/no). "If yes, how many days in the past 12 months?" "How many days have you had sickness absence because of MSD in the past 12 months?" The questions did not distinguish between selfcertification and sickness certification by a physician. It was not distinguished between work days and calendar days, as the shift work makes this more difficult. The outcome of the study was the number of days of sickness absence caused by MSD in the previous 12 months (1-year prevalence). Two indicator variables were constructed: (1) sickness absence 1-12 days because of MSD and (2) sickness absence $>12$ days because of MSD. Sickness absence both less and more than 12 days could include several short spells.

Table I: Frequency of self-reported sickness absence in the previous 12 months among workers reported in $2000(n=3036)$

\begin{tabular}{|c|c|c|c|c|c|c|}
\hline & \multirow[t]{2}{*}{$n$} & \multirow{2}{*}{$\begin{array}{l}\text { \% of workers with } \\
\text { at least I day of } \\
\text { sickness absence }\end{array}$} & \multicolumn{3}{|c|}{ Number of days among workers with absence } & \multirow[t]{2}{*}{$\%$ of total days of sickness absence } \\
\hline & & & $\mathrm{Q}_{\mathrm{L}}{ }^{*}$ & Median & $\mathrm{Q}_{U^{* *}}$ & \\
\hline Total sickness absence & 1850 & {$[61]$} & 3 & 6 & 14 & 100 \\
\hline Sickness absence $\mathrm{I}-12$ days & 1302 & [43] & 3 & 5 & 7 & 23 \\
\hline \multirow[t]{2}{*}{ Sickness absence $>12$ days } & 548 & {$[18]$} & 15 & 23 & 45 & 77 \\
\hline & & & & & & $\begin{array}{l}\% \text { of total days of sickness absence } \\
\text { due to MSD }\end{array}$ \\
\hline $\begin{array}{l}\text { Sickness absence due to } \\
\text { MSD }\end{array}$ & 666 & [22] & 4 & 10 & 20 & 100 \\
\hline $\begin{array}{l}\text { Sickness absence } \mathrm{I}-12 \text { days } \\
\text { due to MSD }\end{array}$ & 399 & {$[13]$} & 3 & 5 & 7 & 16 \\
\hline $\begin{array}{l}\text { Sickness absence }>12 \text { days } \\
\text { due to MSD }\end{array}$ & 267 & [9] & 15 & 25 & 45 & 84 \\
\hline
\end{tabular}

MSD: musculoskeletal disorders $* \mathrm{Q}_{\mathrm{L}}$ lower quartile $* * \mathrm{Q}_{\mathrm{u}}$ upper quartile 
Table 2: Relative risk (RR) with $95 \%$ confidence intervals $(\mathrm{Cl})$ of factors in 1998 that predicted self-reported sickness absence I-I 2 days $(n=399)$ and $>12$ days $(n=267)$ because of MSD in 2000 (total $n=3036)$

\begin{tabular}{|c|c|c|c|c|c|c|c|}
\hline \multirow[t]{2}{*}{ Risk factor (1998) } & \multirow{2}{*}{$\begin{array}{l}\begin{array}{l}\text { Number of } \\
\text { exposed individuals }\end{array} \\
n(\%)\end{array}$} & \multicolumn{3}{|c|}{$\begin{array}{l}\text { Short-term sickness absence ( } 1-12 \text { days) } \\
(2000)(n=399)\end{array}$} & \multicolumn{3}{|c|}{$\begin{array}{l}\text { Long-term sickness absence (> } 12 \text { days }) \\
(2000)(n=267)\end{array}$} \\
\hline & & RR & $P$ & $(95 \% \mathrm{Cl})$ & RR & $P$ & $(95 \% \mathrm{Cl})$ \\
\hline \multicolumn{8}{|l|}{$\begin{array}{l}\text { Pain often/very often } \\
\text { from: }\end{array}$} \\
\hline Neck & $516(17.1)$ & 2.0 & $<0.001$ & $(1.6-2.4)$ & 2.7 & $<0.001$ & $(2.1-3.4)$ \\
\hline Shoulder & $584(19.4)$ & 1.7 & $<0.001$ & $(1.3-2.0)$ & 2.7 & $<0.001$ & $(2.2-3.4)$ \\
\hline Elbow & $187(6.2)$ & 1.6 & 0.005 & $(1.2-2.2)$ & 2.3 & $<0.001$ & $(1.7-3.2)$ \\
\hline Hand & $252(8.4)$ & 1.7 & $<0.001$ & $(1.3-2.2)$ & 2.1 & $<0.001$ & $(1.6-2.8)$ \\
\hline Upper back & $193(6.4)$ & 1.7 & 0.002 & $(1.2-2.2)$ & 2.5 & $<0.001$ & $(1.8-3.3)$ \\
\hline Lower back & $633(21.0)$ & 2.2 & $<0.001$ & $(1.8-2.6)$ & 2.7 & $<0.001$ & $(2.1-3.3)$ \\
\hline Hip & $193(6.4)$ & 1.5 & 0.013 & $(1.1-2.1)$ & 2.5 & $<0.001$ & $(1.8-3.4)$ \\
\hline Knee & $316(10.5)$ & 1.8 & $<0.001$ & $(1.4-2.3)$ & 2.2 & $<0.001$ & $(1.7-2.9)$ \\
\hline Foot & $196(6.5)$ & 2.0 & $<0.001$ & $(1.5-2.6)$ & 2.4 & $<0.001$ & $(1.7-3.3)$ \\
\hline \multicolumn{8}{|l|}{ Widespread pain } \\
\hline No body parts & $1588(52.8)$ & 1.0 & & & 1.0 & & \\
\hline One body part & $570(18.9)$ & 2.1 & $<0.001$ & $(1.6-2.9)$ & 2.3 & $<0.001$ & $(1.7-3.3)$ \\
\hline $\begin{array}{l}\text { Two or more body } \\
\text { parts }\end{array}$ & $852(28.3)$ & 2.8 & $<0.001$ & $(2.3-3.4)$ & 4.5 & $<0.001$ & $(3.4-5.8)$ \\
\hline \multicolumn{8}{|l|}{ Gender } \\
\hline Men & 2585 & 1.0 & & & 1.0 & & \\
\hline Women & $418(13.9)$ & 1.2 & 0.260 & $(0.9-I .5)$ & I.I & 0.40 & $(0.8-1.6)$ \\
\hline \multicolumn{8}{|l|}{ Job category } \\
\hline White collar & 967 & 1.0 & & & 1.0 & & \\
\hline Blue collar & I94I (66.7) & 2.3 & $<0.001$ & $(1.8-2.9)$ & 3.3 & $<0.001$ & $(2.3-4.6)$ \\
\hline \multicolumn{8}{|l|}{ Age (years) } \\
\hline$<30$ & $453(14.9)$ & 1.0 & & & 1.0 & & \\
\hline $30-50$ & $1933(63.8)$ & I.I & 0.34 & $(0.9-1.5)$ & 1.5 & 0.026 & $(1.0-2.2)$ \\
\hline$>50$ & $645(21.3)$ & 0.8 & 0.16 & $(0.6-1.1)$ & 1.4 & 0.10 & $(0.9-2.2)$ \\
\hline Shift work & 1344 (46.4) & 1.4 & 0.001 & $(1.1-1.7)$ & 1.1 & 0.32 & $(0.9-1.4)$ \\
\hline Smoking & $1287(43.3)$ & 1.4 & $<0.001$ & $(1.2-1.7)$ & I.I & 0.24 & $(0.9-1.4)$ \\
\hline \multicolumn{8}{|l|}{ Body mass index (BMI) } \\
\hline Normal (20-24.9) & $1395(46.6)$ & 1.0 & & & 1.0 & & \\
\hline Low $(<20)$ & $65(2.2)$ & 0.8 & 0.50 & $(0.4-1.6)$ & 0.6 & 0.35 & $(0.2-1.8)$ \\
\hline High (>25) & $1532(5 \mid .2)$ & 1.0 & 0.70 & $(0.9-1.2)$ & 1.3 & 0.018 & $(1.0-1.7)$ \\
\hline \multicolumn{8}{|l|}{ Physical activity } \\
\hline$<2$ hours/week & $1169(39.0)$ & 1.0 & & & 1.0 & & \\
\hline 2-5 hours/week & $1319(44.0)$ & 0.8 & 0.032 & $(0.7-1.0)$ & 0.8 & 0.19 & $(0.7-1.1)$ \\
\hline$>5$ hours/week & $508(17.0)$ & 1.0 & 0.76 & $(0.7-1.2)$ & 0.9 & 0.69 & $(0.7-1.3)$ \\
\hline High job strain & 14||$(48.4)$ & 1.7 & $<0.01$ & $(1.4-2.0)$ & 1.9 & $<0.001$ & $(1.5-2.9)$ \\
\hline Low social support & 1171 (39.8) & 1.2 & 0.037 & $(1.0-1.5)$ & 1.0 & 0.80 & $(0.8-1.3)$ \\
\hline
\end{tabular}

\section{Statistical methods}

Univariate analysis including estimation of relative risk (RR) was performed to examine the effects of job category, age, gender, body mass index (BMI), smoking habits, physical activity, shift work, job strain (job demands and control), social support and musculoskeletal symptoms from the neck, shoulders, elbows, hands, upper back, lower back, hips, knees and feet. Median scores on job strain and social support were used to assign subjects to two groups of low and high exposure. The significant variables in the univariate analyses were included in a stepwise Cox regression analysis to study the effect of the factors simultaneously. Sickness absence 1-12 days and sickness absence $>12$ days were analysed separately. Age and gender were included in the final step. The relative risk (RR) and 95\% confidence interval were calculated for each factor.

\section{Results \\ Response}

The follow-up study of workers at the plants was performed in 2000. At this time the plants had fewer workers because of reorganisation. Further, a large number of individuals were not linked from the pre-intervention to the post-intervention because of missing or erroneously filled 
out personal code. A total of 3320 of the 5654 workers were identified in the follow-up survey.

\section{Baseline characteristics}

Most of the workers were blue-collar workers $(67 \%)$ and men $(86 \%)$. Ten percent $(n=218)$ of the blue-collar workers and $21 \%(n=211)$ of the white-collar workers were women. The mean age was 41 years (range 18-64). The proportion of smokers was significantly higher among the blue-collar workers than among the white-collar workers (chi-square, $\mathrm{p}<0.001$ ). The respondents who were linked and included in the study were older than the workers lost in the second survey ( $\mathrm{t}$-test, $\mathrm{p}=0.036$ ), but there was no difference in gender.

\section{Sickness absence}

In 2000, 61\% of the workers reported sickness absence from various causes in the previous year (Table 1). Days of sickness absence from MSD represented $45 \%$ of the total days of sickness absence and $48 \%$ of the long-term sickness absence. The $9 \%$ who had long-term sickness absence from MSD were responsible for $84 \%$ of the days of sickness absence from MSD.

Table 2 shows the risk factors in 1998 associated with the occurrence of sickness absence from MSD reported in 2000. Workers with symptoms from each of the nine parts of the body were at higher risk of both short- and longterm sickness absence, as were blue-collar workers and workers with high job strain. Smokers, shift workers and workers with low social support had a higher risk of shortterm sickness absence. Moderate physical activity was associated with less short-term sickness absence. Workers between 30 and 50 years and workers with high BMI had a moderately increased risk of long-term sickness absence. Gender was not significantly associated with sickness absence.

Widespread pain and low back pain were highly significant in the forward stepwise Cox regression analysis of short-term sickness absence including the significant variables from the univariate analysis (Table 3). Other factors included in the final model were job category and social support. Smoking was significant in the univariate analysis but showed a reduced effect when adjusted for widespread pain in step one in the stepwise regression analysis. Job strain was also significant in the univariate analysis but the effect was reduced when adjusted for social support.

Widespread pain and low back pain were also highly significant predictors of long-term sickness absence from MSD in the stepwise analysis (Table 3). In addition, symptoms from the shoulders independently predicted longterm sickness absence. Job category was highly significant throughout the analysis. Job strain, which was highly significant in the univariate analysis, was excluded when adjusted for job category in the stepwise regression analysis.

Individual factors such as age and gender, which were forced into the model, did not predict sickness absence from MSD. Separate analyses of predictive factors among blue-collar workers and white-collar workers and separate analyses among men and women showed small differences in the risk estimates between the different groups.

Table 3: Cox regression, relative risk (RR) and $95 \%$ confidence intervals $(\mathrm{Cl})$ of factors in 1998 that predicted self-reported days of sickness absence because of MSD less than 12 days and more than 12 days during 2000.

\begin{tabular}{|c|c|c|c|c|c|c|}
\hline \multirow[b]{2}{*}{ Risk factor } & \multicolumn{3}{|c|}{$\begin{array}{l}\text { Short-term sickness absence ( } 1-12 \text { days) ( } n \\
=2824)\end{array}$} & \multicolumn{3}{|c|}{$\begin{array}{l}\text { Long-term sickness absence }(>12 \text { days })(n= \\
3001)\end{array}$} \\
\hline & $\mathbf{R R}$ & $95 \% \mathrm{Cl}$ & $p$ & $\mathbf{R R}$ & $95 \% \mathrm{Cl}$ & $p$ \\
\hline Widespread MSD $(0-10)^{*}$ & 1.15 & $1.07-1.23$ & $<0.001$ & 1.19 & $|.08-1.3|$ & $<0.001$ \\
\hline Shoulders $(I-5)^{*}$ & & & & 1.15 & $1.01-1.32$ & 0.034 \\
\hline Lower back $(\mathrm{I}-5)^{*}$ & 1.24 & $1.11-1.38$ & $<0.001$ & 1.20 & $1.06-1.36$ & 0.005 \\
\hline Blue-collar vs. white-collar workers & 1.96 & $1.49-2.58$ & $<0.001$ & 3.04 & $2.08-4.45$ & $<0.001$ \\
\hline Low social support $(0-I) * *$ & 1.28 & $1.11-1.49$ & 0.001 & & & \\
\hline Women vs. men $(0-I)$ & 1.26 & $0.93-1.7 \mid$ & 0.142 & 0.95 & $0.65-1.40$ & 0.802 \\
\hline $30-50$ vs. $<30$ years & 0.93 & $0.69-1.26$ & 0.647 & 1.12 & $0.74-1.69$ & 0.586 \\
\hline$>50$ vs. $<30$ years $(0-1)$ & 0.71 & $0.48-1.05$ & 0.083 & 1.20 & $0.74-1.94$ & 0.459 \\
\hline
\end{tabular}

* Continuous scale. The relative risk refers to the difference of one step on the scale. ** The relative risk refers to a difference in social support of 0.22 , which is the difference between the lower and upper quartile in the distribution of social support. 


\section{Discussion}

The prevalence of MSD in the aluminium industry is found to be high, and MSD accounted for almost half the working days lost during the previous year among these industrial workers. Studies in the general population have shown similar findings [4]. A small group was responsible for most of the sickness absence, corresponding to similar figures in another Norwegian study [25].

Widespread pain and low back pain were the strongest predictors for both short- and long-term sickness absence from MSD. Complaints from the shoulder also predicted long-term sickness absence. A previous study of the aluminium workers showed a higher frequency of reported symptoms in the lower back than in other parts of the body [17]. This is consistent with findings in a study of patients in general practice in which low back pain and shoulder and neck disorders were the most frequent disorders causing sickness absence [26].

The blue-collar workers in the aluminium industry had a higher risk of sickness absence than the white-collar workers. This has also been found among workers in the general population [12], among patients in general practice [5], among workers in the chemical industry [27] and in a study of sickness absence from low back pain in the metal industry [8]. This might reflect differences in work activities and working conditions between jobs [28]. Since the blue-collar workers in our study had higher sickness absence from MSD also when adjusted for the effect of MSD, this means that also other factors related to bluecollar workers contribute to the increased prevalence of sickness absence. One possible explanation is more difficulty in meeting the demands for physical fitness when MSD is present. Another possible explanation is the effect of such social factors as education and income, which have been found to predict sickness absence among nonindustrial civil servants [13] but were not considered in this study. A more detailed information about physical load or job titles as surrogate measure of this could have given more information whether the increased frequency of sickness absence was mostly related to physical load or socio-economic variables.

High social support had a significant preventive effect on short-term sickness absence. Psychosocial factors seem to be important in predicting short-term sickness absence both among white-collar workers [1] and blue-collar workers [6]. Several studies have shown associations between low social support and MSD [29,30]. The present study shows that high social support prevents short-term sickness absence from MSD among workers independently of the MSD. These findings support the suggestion that short-term sickness absence is an integrated measure of healthy functioning in working populations [1] and a way of coping with poor working conditions in addition to the health problems [2]. High social support seems to allow the workers to work despite musculoskeletal complaints and perceived job strain. Psychosocial factors seemed to be less important in predicting long-term sickness absence.

Shift work did not independently predict sickness absence from MSD in our study. The association between shift work and short-term sickness absence in the univariate analysis was reduced when adjusted for job category, indicating that being a blue-collar worker is the most important predictive factor.

Individual factors such as age and gender did not predict sickness absence from MSD. The minor importance of age in predicting sickness absence from MSD was also found in a study among welders and metal workers [11]. Still, as employees off work at the time of follow up were not included, the low correlation between age and sickness absence might to some degree be explained by a healthy worker selection. Some studies have found higher sickness absence from MSD among women except the diagnosis of low back pain [31,32], but the gender differences decreased markedly after adjusting for sociodemographic factors, job characteristics and income [10]. We compared men and women in the same industry, adjusting for job category, and we found no gender difference.

Physical activity did not seem to independently affect sickness absence from MSD in this population. Although there is evidence that physical activity enhances health [33], literature data on the relationship between leisure physical activity and musculoskeletal symptoms in working populations is still inconsistent [34], and the effect of physical activity on sickness absence seems to be unclear [35]. This relationship has to be studied further.

Smoking was associated with MSD 1-12 days in the univariate analysis. The multivariate analysis showed that smoking did not independently predict sickness absence from MSD when adjusted for job category and low back pain. The possible explanation is that most of the smokers were blue-collar workers, and being a blue-collar worker strongly predicted sickness absence from MSD. Smoking has also been associated with low back pain in several studies $[17,36]$, and low back pain strongly predicted sickness absence in our study.

About 1800 individuals in the second survey were not linked to the individuals from the first survey. Because the response rate was high in both surveys and the plants have relatively low employee turnover, many of these workers may have taken part in both surveys but were not identified. There is no reason to believe that the loss of follow 
up due to missing personal code introduced any bias, as this was primarily related to inaccurate instructions of the code. Others did not respond for unknown reasons. The respondents who participated in the first survey but were lost in the second survey were younger than the linked individuals. However, as age did not significantly predict sickness absence, we assume that the loss to follow-up did not substantially influence the results. Frequency of MSD and sickness absence due to MSD did not differ between the participants and the individuals not identified in the second survey.

The information about sickness absence is self-reported, and the data may lack reliability because of recall bias. The company registers in the different plants did not have complete information about sickness absence, and could not be used in the study. The questionnaire in the present study was answered anonymously. Hence, we could not compare the responses to the company registers of sickness absence. Further, there were no clinical assessments for the complaints underlying the report of sickness absence from MSD. We had information only on the total days of sickness absence during one year and no information about the length of each episode. This makes differentiating between short- and long-term sickness absence more difficult and might be a weakness of the study. The days of sickness absence were not defined as calendar days or as working days lost and may therefore be reported differently by the respondents. Studies on the reliability and validity of questionnaires on sickness absence have shown that questionnaires might be considered a valuable source of information on sickness absence from MSD, specifically for events of more than 14 days $[37,38]$.

Our study may not have adequately considered the complex relationship between the numerous factors that influence sickness absence from MSD such as the role of socioeconomic status, including specific job titles, income, marital status and education $[39,40]$. However, a particular strength of this study is that all the subjects work in the same industry and are comparable for several factors, such as socio-economic factors and work environment. On the other hand, we have already made a high number of comparisons, and we cannot exclude the possibility that some of the associations found are spurious. Sickness absence in 1998 may be a strong predictor of sickness absence in 2000. We did not include sickness absence in 1998 due to the possible problem of overadjustment.

\section{Conclusions}

Blue-collar workers were at higher risk of sickness absence from MSD. Widespread pain and low back pain were the strongest predictors of sickness absence from MSD. Low social support predicted sickness absence 1-12 days among workers with MSD. Individual factors such as age, gender, smoking and physical activity were of minor importance in predicting sickness absence from MSD in this industrial population.

Increased social support at work among industrial workers may have a beneficial effect on short-term sickness absence. Nevertheless, we suggest that the most important strategy seems to be preventing MSD by reducing all the known risk factors for widespread pain and low back pain, including inadequate social support [41]. The working conditions of blue-collar workers including physical and psychosocial risk factors and demands for physical fitness have to be given special attention and to be investigated further.

\section{Competing interests}

None declared.

\section{Authors' contributions}

TM, TR and BM designed the study. SHVH, SH, AL, SP, ILLS, GMS and VT collected the data. TM analyzed the data and wrote up the manuscript. TM, TT and BM revised the manuscript. All authors read and approved the final manuscript.

\section{Acknowledgements}

This project was initiated by the Aluminium Industry in Norway and is a cooperative project between Elkem Aluminium Lista, Elkem Aluminium Mosjøen, Hydro Aluminium Karmøy, Hydro Aluminium Sunndal, Hydro Aluminium Holmestrand, Hydro Aluminium Høyanger, Hydro Aluminium

Årdal, Årdal Carbon, Sør-Norge Aluminium Husnes AS, Aluminiumindustriens Miljøsekretariat and the University of Bergen.

\section{References}

I. Marmot M, Feeney A, Shipley M, North F and Syme SL: Sickness absence as a measure of health status and functioning: from the UK Whitehall II study. J Epidemiol Community Health 1995, 49(2): $124-130$.

2. Kristensen TS: Sygefravær som coping. Socialmed tidskr 1995:12-17.

3. Takala J: Introductory report of the International Labour Office. International Occupational Safety and Health Information Centre. Geneva: International Labour Office. 1999.

4. Tellnes G: Days lost by sickness certification. Scand J Primary Health Care 1989, 7:245-25I.

5. Tellnes G, Bruusgaard D and Sandvik L: Occupational factors in sickness certification. Scand J Primary Health Care I 990, 8(I):37-44.

6. Kristensen TS: Sickness absence and work strain among Danish slaughterhouse workers: an analysis of absence from work regarded as coping behaviour. Soc Sci Med I99I, 32:15-27.

7. Rael EG, Stansfeld SA, Shipley M, Head J, Feeney A and Marmot M: Sickness absence in the Whitehall II study, London: the role of social support and material problems. J Epidemiol Community Health 1995, 49(5):474-48I.

8. Wickstrom GJ and Pentti J: Occupational factors affecting sick leave attributed to low-back pain. Scand J Work Environ Health 1998, 24(2): I 145-152.

9. Hemingway H, Shipley MJ, Stansfeld S and Marmot M: Sickness absence from back pain, psychosocial work characteristics and employment grade among office workers. Scand J Work Environ Health 1997, 23(2): 121-129.

10. Brage S, Nygard JF and Tellnes G: The gender gap in musculoskeletal-related long-term sickness absence in Norway. Scand J Soc Med 1998, 26(I):34-43. 
11. Burdorf A, Naaktgeboren B and Post W: Prognostic factors for sickness absence from MSD and return to work among welders and metal workers. Occup Environ Med 1998, 55:490-495.

12. Brage S, Bjerkedal T and Bruusgaard D: Occupational-specific morbidity of musculoskeletal disease in Norway. Scand J Soc Med 1997, 25(I):50-57.

13. North F, Syme SL, Feeney A, Head J, Shipley Mj and Marmot MG: Explaining socioeconomic differences in sickness absence: the Whitehall II Study. BMJ 1993, 306:36I-366.

14. Karasek R and Theorell T: Healthy work. Stress, productivity, and the reconstruction of life. New York: Basic Books 1990.

15. Voss M, Floderus B and Diderichsen F: Physical, psychosocial, and organisational factors relative to sickness absence: a study based on Sweden Post. Occup Environ Med 200I, 58(3): I78-I84.

16. Ursin H, Endresen IM, Svebak S, Tellnes G and Mykletun R: Muscle pain and coping with working life in Norway: a review. Work \& Stress 1998, 7(3):247-258.

17. Morken T, Moen BM, Riise T, Bergum O, Bua L, Hauge SHV, Holien S, Langedrag A, Olson HO, Pedersen S, Saue ILL, Seljebø GM and Thoppil V: Prevalence of musculoskeletal symptoms among aluminium workers. Occup Med 2000, 50(6):4|4-42|.

18. Luz J and Green MS: Sickness absenteeism from work - a critical review of the literature. Pub Health Rev 1997, 25(2):89-122.

19. Blank $N$ and Diderichsen F: Short-term and long-term sick-leave in Sweden: relationships with social circumstances, working conditions and gender. Scand / Soc Med 1995, 23(4):265-272.

20. Morken T, Moen BE, Riise T, Hauge SHV, Holien S, Langedrag A, Olson HO, Pedersen S, Saue ILL, Seljebø GM and Thoppil V: Effects of a training program to improve musculoskeletal health among industrial workers. Int $J$ Ind Ergonomics 2002, 30:1 I5- 127.

21. Kuorinka I, Jonsson B and Kilbom A: Standardized Nordic questionnaires for the analysis of musculoskeletal symptoms. App Ergonomics 1987, 18:233-237.

22. Holmstrom E and Moritz U: Low back pain - correspondence between questionnaire, interview and clinical examination. Scand J Rehabil Med I991, 23(3): I 19-125.

23. Theorell T, Michelsen H, Nordemar R and Stockholm MUSIC I Study Group: Tre arbetsmiljöindeks som anvents i Stockholmsundersøkningen I. In: Stockholmsundesökningen I. Data från en tvärsnitsundersökning av ergonomisk og psykosocial exponering samt sjuklighet og funktion i rörelsesorganen Edited by: Hagberg M, Hogstedt C. Stockholm: MUSIC Books; I991:I50-I54

24. Karasek R, Brisson C, Kawakami N, Houtman I, Bongers P and Amick B: The Job Content Questionnaire (JCQ): an instrument for internationally comparative assessments of psychosocial job characteristics. J Occup Health Psychol 1998, 3(4):322-355.

25. Tveito T, Halvorsen A, Lauvålien JV and Eriksen HE: Room for everyone in working life? $10 \%$ of the employees $-82 \%$ of the sickness leave. Norsk Epidemiologi 2002, I 2(I):63-68.

26. Reiso H, Nygard JF, Brage S, Gulbransen P and Tellnes G: Work ability and duration of certified sickness absence. Scand J Public Health 200I, 29(3):2I8-225.

27. Kleiven $M$, Boggild $H$ and Jeppesen $H J$ : Shift work and sick leave. Scand J Work Environ Health 1998, 24(suppl 3): I28-133.

28. Hughes RE, Silverstein $B A$ and Evanoff $B A$ : Risk factors for workrelated musculoskeletal disorders in an aluminum smelter. Am J Ind Med 1997, 32(I):66-75.

29. Bongers PM, de Winter CR, Kompier MA and Hildebrandt VH: Psychosocial factors at work and musculoskeletal disease. Scand J Work Environ Health 1993, 19(5):297-3 2 .

30. Toomingas A, Theorell T, Michelsen $\mathrm{H}$ and Nordemar R: Associations between self-rated psychosocial work conditions and musculoskeletal symptoms and signs. Stockholm MUSIC I Study Group. Scand I Work Environ Health 1997, 23(32): I30-139.

31. Leijon M, Hensing $G$ and Alexanderson K: Gender trends in sicklisting with musculoskeletal symptoms in a Swedish county during a period of rapid increase in sickness absence. Scand J Soc Med 1998, 26(3):204-213.

32. Sandanger I, Nygard JF, Brage S and Tellnes G: Relation between health problems and sickness absence: gender and age differences - a comparison of low-back pain, psychiatric disorders, and injuries. Scand J Public Health 2000, 28(4):244-252.

33. Vuori I: Does physical activity enhance health? Patient Educ Couns 1998, 33(I Suppl): $95-103$.

34. Hildebrandt VH, Bongers PM, Dul J, van Dijk FJ and Kemper HC: The relationship between leisure time, physical activities and musculoskeletal symptoms and disability in worker populations. Int Arch Occup Environ Health 2000, 73(8):507-5 I8.

35. Alvestad B, Jenssen HN, Larun L, Palner J, Rosberg A and Saetre U: [Does physical exercise at the workplace have any effect on sick leave?]. Tidsskr Nor Laegeforen 1998, I I 8(I I): I7I 8-172I.

36. Goldberg MS, Scott SC and Mayo NE: A review of the association between cigarette smoking and the development of nonspecific back pain and related outcomes. Spine 2000, 25(8):995-1014.

37. Burdorf A, Post $W$ and Bruggeling $T$ : Reliability of a questionnaire on sickness absence with specific attention to absence due to back pain and respiratory complaints. Occup Environ Med 1996, 53(I):58-62.

38. Fredriksson K, Toomingas A, Torgen M, Thorbjornsson CB and Kilbom $A$ : Validity and reliability of self-reported retrospectively collected data on sick leave related to musculoskeletal diseases. Scand J Work Environ Health 1998, 24(5):425-43I.

39. North FM, Syme SL, Feeney A, Shipley M and Marmot M: Psychosocial work environment and sickness absence among British civil servants: the Whitehall II study. Am J Public Health 1996, 86(3):332-340.

40. Dionne CE, Von Korff M, Koepsell TD, Deyo RA, Barlow WE and Checkoway $\mathrm{H}$ : Formal education and back pain: a review. J Epidemiol Community Health 200I, 55(7):455-468.

4I. Hoogendoorn WE, van Poppel MN, Bongers PM, Koes BW and Bouter LM: Systematic review of psychosocial factors at work and private life as risk factors for back pain. Spine 2000, 25(I6):2II4-2I25.

\section{Pre-publication history}

The pre-publication history for this paper can be accessed here:

http://www.biomedcentral.com/1471-2474/4/21/prepub
Publish with Bio Med Central and every scientist can read your work free of charge

"BioMed Central will be the most significant development for disseminating the results of biomedical research in our lifetime. "

Sir Paul Nurse, Cancer Research UK

Your research papers will be:

- available free of charge to the entire biomedical community

- peer reviewed and published immediately upon acceptance

- cited in PubMed and archived on PubMed Central

- yours - you keep the copyright

Submit your manuscript here:

http://www.biomedcentral.com/info/publishing_adv.asp
BioMedcentral 